\title{
Radial club hand managed with ulnar osteotomy and centralization of hand: a case report and review
}

\section{Pradeep Kamboj, Mayukh Mukherjee*, Jitendre Wadhwani, Rahul Sharma, Mayank Jain, Kunal Arora, Aksha Mohan Garg, Abhay Tanwar, Gaurav Agarwal}

Department of Orthopaedics, Pt. B.D. Sharma PGIMS, Rohtak, Haryana, India

Received: 27 September 2021

Revised: 29 October 2021

Accepted: 03 November 2021

\section{*Correspondence:}

Dr. Mayukh Mukherjee,

E-mail: drmayukh780@gmail.com

Copyright: () the author(s), publisher and licensee Medip Academy. This is an open-access article distributed under the terms of the Creative Commons Attribution Non-Commercial License, which permits unrestricted non-commercial use, distribution, and reproduction in any medium, provided the original work is properly cited.

\begin{abstract}
Radial club hand also called radial longitudinal deficiency or radial dyspasia is a preaxial longitudinal failure of formation. As the defect is preaxial it is often associated with thumb hypoplasia or anomaly of the radial aspect of the carpus. It is diagnosed clinically and on X-rays. It is frequently syndromic so it is a must to look for associated congenital anomalies by doing a through clinical examination. The frequency of this anomaly is between 1:50000 to 1:100000 live births. The incidence of all radial ray-deficient limbs, including hypoplastic thumbs alone, is approximately 1:30000. The radial deficiency is bilateral in 50\% of the cases and the male:female is 3:2. It includes a wide spectrum of disorders that encompass an absent thumb or thumb hypoplasia, a thin first metacarpal and an absent radius. We report here a 1.5 years old child with isolated type IV radial club hand without any restricted range of motion in elbow managed with osteotomy of ulna and centralization of hand.
\end{abstract}

Keywords: Radial club hand, Ulnar osteotomy, Hand

\section{INTRODUCTION}

Club hand deformities can be either preaxial or postaxial. Preaxial is radial defect whereas postaxial is ular defect. Radial club hand or radial dysplasia is an uncommon congenital anomaly. It is a longitudinal deficiency along the preaxial or the radial aspect of the upper extremity. The frequency of this anomaly is between 1:50000 to 1:100000 live births. The incidence of all radial ray-deficient limbs, including hypoplastic thumbs alone, is approximately 1:30000. The radial deficiency is bilateral in $50 \%$ of the cases and the male:female is 3:2. ${ }^{1}$ It includes a wide spectrum of disorders that encompass an absent thumb or thumb hypoplasia, a thin first metacarpal and an absent radius. $^{2}$ The radial ray which includes radius, scaphoid, trapezium, thumb and associated soft tissue structures of which all or part can be missing depending on severity. The median nerve lies very superficial at the level of wrist. Other muscles in upper limb may be absent, abnormal or accessory like presence of brachiocarpalis in forearm, consistently found in patients with TAR syndrome. ${ }^{3}$ The radial artery is absent in $86.5 \%$ of the cases with a normal ulnar artery. A significant of cases have a persistent embryogenic median artery of the upper limb. Several theories are postulated like maternal exposure to valproic acid, compression of the uterus and vascular injury, but the current theory relates the aetiology of the radial club hand to the apical ectodermal ridge (AER) which is a thickened layer of ectoderm that directs the differentiation of the underlying mesenchymal tissue and limb formation. ${ }^{4}$ Removal of a portion of AER in chick embryos has produced anomalies which are similar to the radial club hand. The extent of the deformity is related to the degree and extent of AER absence. ${ }^{5}$ Various gene defects have been identified in syndromic associations like mutation of TXB in chromosome 12 in Holt-Oram syndrome, two abnormal FANC gene in Fanconi anaemia. ${ }^{5,6}$ Heikel, based on the amount of the radius which was present, classified 
radial dysplasia into four types, ranging from a present but defective distal radial epiphysis (Type I) to a complete absence of the radius (Type IV). TYPE I: mildest form with defective distal radial epiphysis, TYPE II: Involves a limited growth of the radius on both its distal and proximal sides, TYPE III: Absence of two-thirds of the radius, most commonly the distal side and TYPE IV: Complete absence of the radius along with a complete or a near complete absence of the thumb, which is the most common and most severe longitudinal deficiency. ${ }^{7}$

Treatment is usually based on age with splinting being effective and well tolerated till 6 months of age. Beyond this till 18 months a stretching program for the parents to the child is recommended combined with night splinting. Stretching and splinting should be started early in infancy to maintain soft tissue length. Beyond 18 months conservative procedures are not effective and surgical intervention is done. Operative procedure includes use of a bilobed flap, soft tissue release, ulnar osteotomy, and temporary longitudinal wiring of the carpus to the distal end of the ulna in the corrected position as done in our case. Hypoplastic thumb is managed either by web space lengthening for Blauth type 1 defects, additional opponensplasty and ulnar collateral ligament reconstruction for type 2 , tendon transfer for type $3 \mathrm{~A}$. For Blauth 3B, 4 and 5 we wait till age of 2 years and perform policization of a fuctional index finger. Other methods include radialisation which in itself is a modification of centralization with radial sided tendons transferred ulnarly. Ilizarov correction can be used to lengthen ulna through osteotomy in conjunction with realignment procedures. Vascularised epiphyseal transfer of a metatarsophalangeal joint unit from foot to the radial side of wrist is done via microsurgical techniques8.Surgically acceptable postoperative period may not be satisfactory in long run due to recurrence of deformity or arrest of distal ulnar growth brought on by surgery. Contraindications for the operative treatment includes life threatening anomalies which are not compatible with long life, ulnohumral synostosis, mild deformity with adequate radial support (type I and some type II), and older patients who have accepted the deformities and have adjusted accordingly. ${ }^{9}$ So, keeping in mind the above facts, the present case report and review was conducted to manage the radial club hand with ulnar osteotomy.

\section{CASE REPORT}

A 1 year 6 months old male child was brought to the OPD at Pt. B. D. Sharma PGIMS, Rohtak, Haryana, with a history of a deformed left upper limb in the form of a short, curved, left forearm and a hypoplastic thumb since birth. He was a product of a non-consanguineous marriage and his perinatal history was uneventful. There was no history of blood transfusion. There was no family history of a similar deformity in the past two generations. He is developmentally normal for his age and compared to other siblings. He was anthropometrically within normal limits. The physical examination of the child revealed an atrophied and shortened left forearm as compared to the opposite normal limb and he had a single forearm bone with a curvature laterally. The movements of the left elbow flexion and extension were normal. All the distal movements including the rotatory movements of the forearm and the wrist and the fine finger movements were possible. The thumb was hypoplastic (Figure 1). The systemic examination was normal. Evaluation of the radiographs of both the upper limbs revealed complete aplasia of the left radius and hypoplasia of the first digit (thumb) of the left hand, including its metacarpal and the phalanges. The ulna on the affected side was shorter than that on the contra lateral side and there was radial deviation at the wrist (Figure 2). Chest X-ray, echocardiogram, hemogram including the platelet count, and ultrasound of the abdomen were normal. Parents were explained the need of reconstruction surgery and the benefit of intervention at an early age to which they agreed. He was operated under general anaesthesia with osteotomy of ulna at midshaft level with $\mathrm{K}$-wire fixations to centralize the ulnar bone (Figure 3). Intra operative and post operative periods were uneventful and he was discharged on day 5 of post operative period.

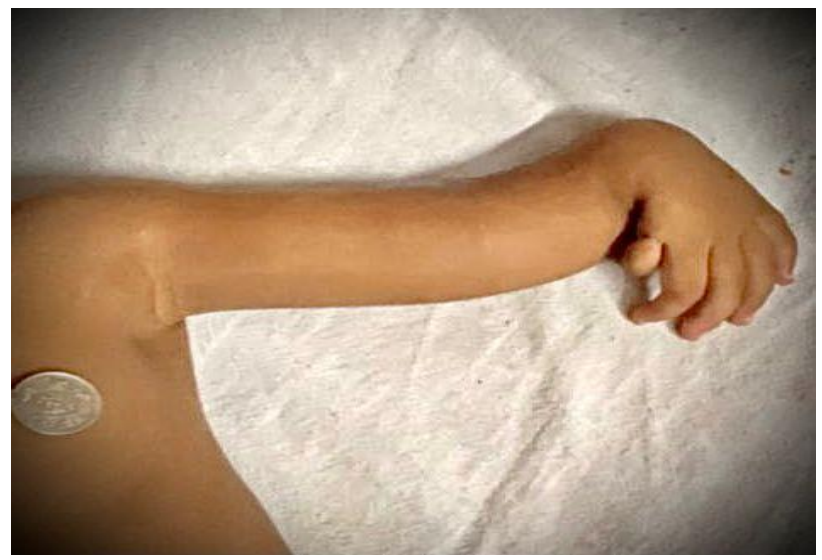

Figure 1: Short left forearm with hypoplastic thumb and radial deviation of hand.

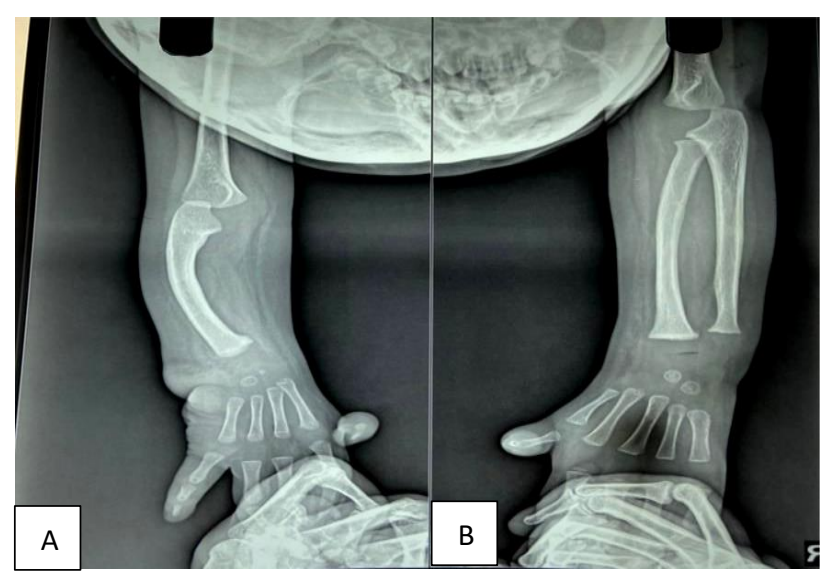

Figure 2 (A and B): X-ray of left upper limb of complete absence of radius and hypoplastic thumb with radial deviation wrist and ulnar bowing. 


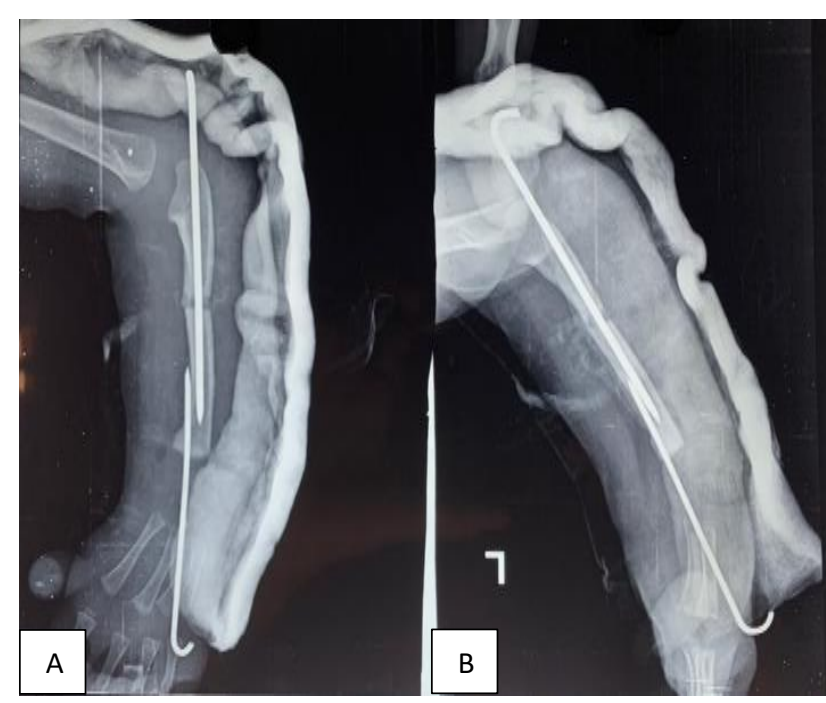

Figure 3 (A and B): Post-operative X-ray of ulnar osteotomy and centralisation of ulna with $\mathrm{K}$-wire fixation.

\section{DISCUSSION}

Our case was unilateral radial club hand type IV with a complete absence of the radius, along with a hypoplastic thumb. Due to the availability of better medical facilities and awareness among parents, most of the radial club hands are diagnosed during the first year of life, with a better functional outcome after reconstructive surgery as in our case..$^{10,11}$ Although radial deficiency can occur in isolation, it is many times associated with other congenital malformations. Forty per cent of the patients with unilateral club hand and $27 \%$ with bilateral club hand have associated congenital anomalies involving the cardiac, genitourinary, skeletal, craniofacial and the haematopoietic system. ${ }^{12}$ Our case didn't have any associated congenital anomaly. In Radial club hand, the forearm is foreshortened, with a marked curving of the forearm, stiffness of the elbow and fingers, with the wrist being positioned in radial deviation, and the thumb being either small or absent. ${ }^{13}$ The cardiac, genitourinary, skeletal and haematopoietic system involvement requires clinical, radiographic, echocardiogram and laboratory evaluation as appropriate. The commonly associated syndromes include:

\section{Holt Oram syndrome}

Radial dysplasia is associated with congenital heart disease (usually ASD or VSD). Abnormalities of the radius can occur in association with heart disease, but do not qualify as the Holt Oram syndrome when they are not bilateral, they lack the carpal changes and are associated with other visceral malformations and cardiac malformations which are different from intracardiac shunts, conduction disturbances or pulmonary hypertension which are characteristic of the Holt Oram syndrome.

\section{Thrombocytopaenia absent radius (TAR) syndrome}

It has an autosomal recessive inheritance. The thrombocytopenia is present at birth. It is differentiated from other conditions by the presence of the thumb.

\section{VACTERLS association}

Each letter in this syndrome's name constitutes an acronym for the defects which are involved: vertebral, anal, cardiac, tracheoesophageal, renal, limb and single umbilical artery. Babies who have been diagnosed with the VACTERLS association usually have at least three or more of these individual anomalies.

\section{Cornelia de Lange syndrome}

Children who are affected by this syndrome are usually growth retarded and they have microcephaly, classic facial features, micromelia, sensorineural hearing loss, genitourinary abnormalities and behavioural problems. ${ }^{14}$

\section{Fanconi's anaemia}

It is also a rare autosomal recessive disease. In infancy, there are the usual characteristic facial features (microphthalmos, strabismus and hearing defects). Pancytopaenia usually does not present until later in childhood, with the mean age of onset being 8 years. There is an increased susceptibility to malignancy, particularly leukaemia. ${ }^{15}$

Other associations include Seckel's syndrome and an association with trisomies. ${ }^{13,17,18}$

Our case had isolated radial club hand and didn't fit into any of the above-mentioned defined syndromes. Whenever a club hand is identified, it is imperative to conduct a thorough examination and a diagnostic evaluation of the new born to delineate the associated anomalies that may suggest a syndrome. Once the birth defects have been identified, a treatment plan needs to be developed for the infant, with the gastrointestinal, renal and cardiac anomalies usually requiring early surgical management. If the patient survives these surgeries, the prognosis is usually good. The orthopaedic abnormalities can be treated individually. In our case, the child was younger, with deformities in the left upper limb and no contracture at the elbow joint. He was an ideal case to operate on for a better functional outcome. However, documentations are there for successful corrective surgery, even in older children with radial club hand. ${ }^{16}$

\section{CONCLUSION}

Whenever a club hand is identified, it is imperative to conduct a thorough examination and evaluation of the new born to delineate the associated anomalies that may suggest a syndrome, because an early diagnosis and appropriate treatment have a better outcome. 
Funding: No funding sources

Conflict of interest: None declared

Ethical approval: No required

\section{REFERENCES}

1. Bayne LG, Klug MS. Long term review of the surgical treatment of radial deficiencies. J Hand Surg Am 1987;12:169-70.

2. Romero R, Athanassiadis AP, Jeanty P. Fetal skeletal anomalies. Radiol Clin North Am. 1989;28:94-5.

3. Oishi SN, Carter P, Bidwell T. Thrombocytopenia absent radius syndrome: presence of brachiocarpalis muscle and its importance, J Hand Surg Am. 2009;34:1696-8.

4. Pike JM, Manske PR, Steffen JA. Ulnocarpal epiphyseal arthrodesis for recurrent deformity after centralization for radial longitudinal deficiency. J Hand Surg Am. 2010;35:1755-6.

5. Kozin SH. Radial Club hand. Available at: http://emedicine.medscape.com/article/1243998overview. Accessed on 25 May 2021.

6. Bonnet D, Terrett J, Pequignot-Viegas E. Gene localization in $12 \mathrm{q} 12$ in Holt-Oram atrio-digital syndrome. Arch Mal Coeur Vaiss. 1995;88:661-4.

7. Heikel HVA. Aplasia and hypoplasia of the radius. Acta Orthop Scand. 1959;39:1.

8. Vilkki SK. Distraction and microvascular epiphysis transfer for radial club hand. J Hand Surg Br. 1998;23:445.
9. Tonkin MA. Radial Longitudinal Deficiency (radial dysplasia, radial club hand). In: Green OP, Hotchkiss $\mathrm{RN}$, Pederson WC, eds. Greens operative hand surgery, 4th edition New York: Churchill Livingstone, 1999;344-6.

10. Salati SA, Rabah SM. Congenital isolated right radial club hand. Libyan J Med. 2010;5:5090.

11. Farzan M., Mortazavi SMJ. Congenital radial club hand: result of centralization in 10 cases. Acta Medica Iranica. 2005;43:63-7.

12. Kozin SH. Upper-extremity congenital anomalies. J Bone Joint Surg Am. 2003;85:1564-76.

13. Skerik SK, Flatt AE. The anatomy of congenital radial dysplasia. Its surgical and functional implications. Clin Orthop Relat Res. 1969;66:125-43.

14. Alman BA, Goldberg MJ. Syndromes of Orthopaedic Importance. In: Morrissy RT, Weinstein SL, eds. Lovell and Winters Paediatric Orthopaedics. 5th ed. Lippincott Williams and Wilkins. 2001;287-338.

15. Goldstein R. Hypoplastic anemia with multiple congenital anomalies (Fanconi's Syndrome). Am J Dis Child. 1955;89:618-9.

16. Walia J, Singh R. Radial club hand-A case report. Indian J Orthop. 2006;40:267-8.

Cite this article as: Kamboj $\mathrm{P}$, Mukherjee M, Wadhwani J, Sharma R, Jain M, Arora K et al. Radial club hand managed with ulnar osteotomy and centralization of hand: a case report and review. Int J Res Orthop 2022;8:102-5. 